\title{
Degradation of petroleum diesel fuel accelerated by UV irradiation: the impact of ageing on chemical composition and selected physicochemical properties
}

\author{
Rafał Janus ${ }^{1,2, *}$, Karol Kołomański ${ }^{1,2}$, Mariusz Wądrzyk ${ }^{1,2}$, and Marek Lewandowski ${ }^{1,2}$ \\ ${ }^{1}$ AGH University of Science and Technology, Faculty of Energy and Fuels, al. A. Mickiewicza 30, \\ 30-059 Krakow, Poland \\ ${ }^{2}$ AGH University of Science and Technology, AGH Centre of Energy, ul. Czarnowiejska 36, \\ 30-054 Krakow, Poland
}

\begin{abstract}
The long-term chemical stability of diesel fuel during storage is one of the key factors, which enable the proper operation of the combustion engine and, therefore, may prolong its life. The progressive degradation of particular components of diesel can affect negatively their physicochemical parameters, what, in turn, entails the issues with regular work and performance of the engines and influences adversely the composition of the exhaust. Moreover, the ageing results in the formation of high molecular polymers that form troublesome sediments which cover the bottom of the container and disrupt the injection of the fuel to the combustion chamber. The present study was aimed to investigate the changes in the chemical composition of the conventional petroleum diesel fuel stored with unrestricted air access under UV irradiation $(\lambda=254 \mathrm{~nm})$. The changes in the chemical composition were determined by means of gas chromatography coupled to mass spectrometry. The changes in the crucial physicochemical parameters, namely: density, viscosity, flash point, cloud point, cetane number, cetane index, and distillation characteristic, caused by the photochemical degradation of diesel components, were discussed with regard to the changes in the molecular composition of diesel.
\end{abstract}

\section{Introduction}

Although the use of diesel oil in the transportation sector has an unambiguously negative impact on the environment, this fuel still remains the leader in terms of consumption among all the commercial liquid fuels. In 2017 the diesel' car share in the EU market reached approximately $44 \%$ [1]. Furthermore, worldwide diesel engine sales are forecast to expand by $5.8 \%$ per year until 2020 [2].

Petrodiesel is a complex mixture of saturated hydrocarbons ( $n$ - and isoparaffins as well as naphthenes), aromatics, and olefins that typically contain 10-20 carbon atoms in the molecule. As a consequence, the boiling temperature ranges within $180-350{ }^{\circ} \mathrm{C}$, while the

\footnotetext{
* Corresponding author: rjanus@agh.edu.pl
} 
higher heating value typically reaches approximately $42-44 \mathrm{MJ} / \mathrm{kg}$ [3]. The base fossil diesel is composed of the fractions obtained by the primary and secondary processing of crude oil [3].

As diesel fuel contains certain amounts of highly reactive unsaturated compounds, the chemical composition of the fuel undergoes changes during long-term storage. The degradation of particular components can affect negatively the physicochemical parameters, what, in turn, may entail some issues with regular work and performance of the combustion engines [4]. Moreover, the ageing results in the formation of high molecular polymeric species, which form troublesome sediments covering the bottom of the fuel tank and disrupt the injection of the fuel to the combustion chamber, as well as the combustion process (e.g. different temperature and air to fuel ratio etc.), and as a consequence emission of hazardous compounds [5]. Additionally, acidic products accelerate the degradation of engine elements, causing corrosion and shortening its lifetime.

The kinetics of the chemical transformations of the middle distillate fuels is governed by its composition and storage conditions, i.e. (i) amount of reactive organic species, (ii) content of biocomponents, especially with heteroatoms, i.e. O- and N-compounds [6], (iii) presence of water and microorganisms, which readily growth on the water-oil phase interface, (iv) contact with metals like $\mathrm{Cu}, \mathrm{Zn}$ or their alloys, i.e. brass [7], (v) presence of various additives (antioxidants, biocides etc.), (vi) exposure to the light, especially in the range of UV radiation, and (vii) average storage temperature.

Generally, diesel fuel is considered to be applicable for fuelling the compression ignition engines for 12 months when stored at room temperature (approximately $20^{\circ} \mathrm{C}$ ) and for $6-12$ months at the temperatures above $30^{\circ} \mathrm{C}[7]$.

The long-term chemical stability of diesel may be improved to some extent by the use of small amounts of proper fuel stability additives, which may be overall classified in three following groups: (i) metal deactivators; their role is to sequestrate the undesirable metal ions via chelation, (ii) antioxidants, which inhibit/terminate the reactions of oxidation of reactive diesel components, and (iii) biocides, whose role is to prevent the growth of fungi and bacteria in the fuel. Additionally, the stability may be prolonged by the use of stabilizers, i.e. demulsifiers, employed for breaking down the water-oil emulsions and dispersants, which prevent the formation of solid-phase agglomerates and sediments. An interesting solution designed to enhance the stability of diesel was the use of so-called fuel stability foam, proposed by Power et co-workers [8]. This original invention was based on the adsorptive removal of polar compounds formed during fuel storage on the polyurethane foams immersed in the fuel.

The present study was aimed to investigate the changes in the chemical composition of conventional diesel fuel stored with unrestricted air access under UV irradiation $(\lambda=254 \mathrm{~nm})$. The chemical composition of fuel was examined by means of gas chromatography coupled to mass spectrometry. The changes of the pivotal parameters (i.e. density, viscosity, flash point, cloud point, cetane number, cetane index, and distillation characteristic) caused by the photochemical degradation, were discussed with regard to the changes in the molecular composition.

\section{Experimental section}

\subsection{Materials}

The subject of the study was the sample of commercially available petrodiesel (without any biocomponent additives) purchased from one of the domestic (Polish) manufacturers. The sample was stored in a $2 \mathrm{~L}$ polypropylene canister in a laboratory refrigerator kept at $4{ }^{\circ} \mathrm{C}$. 
The ageing tests were carried out as follows. Two portions of $100 \mathrm{~mL}$ of the sample were put into two $250 \mathrm{~mL}$ beakers. One of them (the reference sample) was stored without sealing, with unrestricted air access at room temperature $\left(20^{\circ} \mathrm{C}\right)$, while the second one was additionally exposed to UV irradiation $(\lambda=254 \mathrm{~nm})$. The fuels were aged for a period of 30 days. The samples taken for analysis were denoted as D-0 (fresh fuel), D-30 (the sample aged for 30 days without UV irradiation), and D-30-UV (UV-irradiated sample, aged for 30 days). Additionally, in order to recognize the changes that undergo in the chemical composition during ageing, the samples were taken to GC-MS analysis at regular six-days intervals.

\subsection{Characterization methods}

\subsubsection{Chemical composition}

The qualitative and semiquantitative analysis of the studied samples was performed by means of gas chromatography coupled to mass spectrometry (GC-MS). The analyses were carried out on GC Agilent apparatus GC 7890B equipped with an MS 5977A mass spectrometer. The Agilent DB-17 capillary column $(30 \mathrm{~m} \times 0.32 \mathrm{~mm} \times 0.5 \mu \mathrm{m})$ was used. Prior to the analysis, the sample was vigorously agitated (to allow the dissolution of the formed sediments) and diluted to $5 \mathrm{wt}$. \% with hexane (Avantor Performance Materials Poland; HPLC grade). The temperature of GC inlet was kept at $300^{\circ} \mathrm{C}$, while the temperature regime of $\mathrm{GC}$ oven consisted in the heating from $40^{\circ} \mathrm{C}$ up to $260^{\circ} \mathrm{C}$ at a constant heating rate of $3{ }^{\circ} \mathrm{C} / \mathrm{min}$. Helium (grade 6.0) was used as carrier gas at a constant flow of $1.0 \mathrm{~mL} / \mathrm{min} .2 .0$ $\mu \mathrm{l}$ of a sample was injected into the GC column at a split of 10:1. The temperature of the MS ion source was kept at $230{ }^{\circ} \mathrm{C}$, while the electron ionization energy was set at $70 \mathrm{eV}$. The MS spectra were scanned within the $\mathrm{m} / \mathrm{z}$ range of 28-500 and analyzed using the chemical database G1034C as the reference MS library. The threshold for the match factors in the library search routines was $75 \%$. The relative concentrations of the determined groups of compounds were calculated as a ratio of a particular peak area to the total peak area of all detected compounds. The peak areas were calculated in the total ion mode (TIC).

\subsubsection{Physicochemical parameters}

Density of the samples was determined at $15^{\circ} \mathrm{C}$ by means of a pycnometric method according to PN-EN ISO 3838:2008 standard. The pycnometer was calibrated using deionized water as the reference.

Kinematic viscosity was examined in accordance with the PN-EN ISO 3104 standard at $40{ }^{\circ} \mathrm{C}$ using the Ubbelohde capillary viscometer, which principle is based on the HagenPoiseille law. The method consists in measuring the time of outflow of a given volume of liquid through the vertically-oriented capillary at a given temperature. The kinematic viscosity is calculated as the product of the time of outflow and the constant of the capillary. Flash point was determined using an Eraflash instrument (Eralytics $\mathrm{GmbH}$, Austria) working with a continuously closed cup, accordingly to ASTM D7094, in which flash point is determined by measuring the rapid pressure change inside the closed cup filled with a sample, which is being heated and exposed to electric spark (a sudden increase in pressure caused by detonation signals reaching the flash temperature). Amount of $2.00 \mathrm{~mL}$ of a sample was placed in a metal crucible equipped with a magnetic stirrer. After closing the crucible, the sample was heated and stirred, and the electric spark was delivered above the liquid every $1{ }^{\circ} \mathrm{C}$ of temperature increment until the ignition of the fuel vapor. The collected results were automatically recalculated to PN-EN ISO 2719:2016 standard. 
Cloud point was determined by means of a 70xi analyzer (Phase Technology, Canada) working according to ASTM D5773 standard. The measurement consists in the recording of the changes in the intensity of the light beam passing through the sample during its cooling down. The appearance of the crystals of fuel components near cloud point results in the attenuation of the intensity of the light beam.

Cetane number and cetane index were assessed based on the estimation of the chemical composition and density made by the juxtaposition of the IR spectra collected for the samples with the IR fuel reference library with the use of relevant mathematical algorithms. The spectra were recorded in a wavenumber region of $650-4000 \mathrm{~cm}^{-1}$ on an Eraspec analyzer (Eralytics GmbH, Austria).

Atmospheric distillation characteristic was collected using an ADU 4 automatic distillation unit (Petrotest GmbH, Germany). Amount of $100.00 \mathrm{~mL}$ of sample was placed in a $150 \mathrm{~mL}$ round-bottom distillation flask equipped with a thermocouple. Then, the flask was installed in the furnace and the sample was heated up to $360{ }^{\circ} \mathrm{C}$ at a programmed heating rate, which provided the distillation rate of $6 \mathrm{~mL} / \mathrm{min}$ until the sample reached the final boiling point.

\section{Results and discussion}

\subsection{Evolution of chemical composition}

The quantitative composition of the studied samples was determined by GC-MS. The TIC chromatograms collected for fresh fuel and the samples after 30 days of ageing with and without UV irradiation are depicted in Fig. 1.

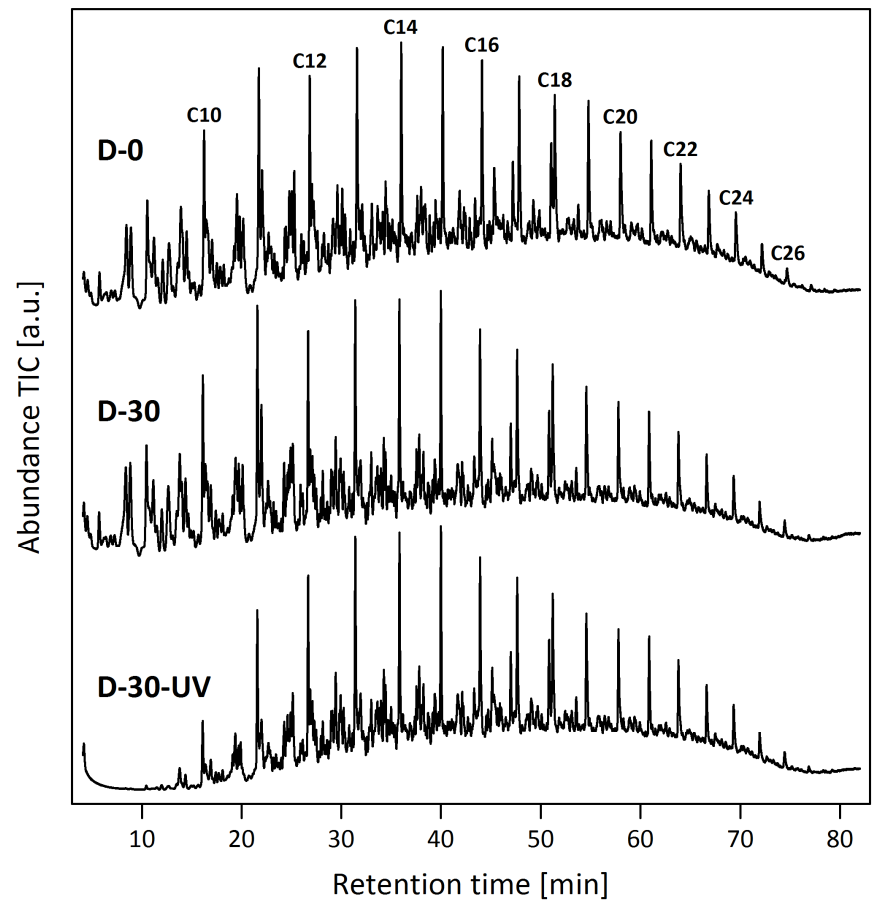

Fig. 1. GC-MS TIC chromatograms recorded for D-0, D-30, and D-30-UV samples.

The set of characteristic sharp and intense peaks presented in Fig. 1., marked as $\mathrm{C} x$ (where $x$ suffix refers to the number of carbon atoms in the molecule), is related to the homologous 
series of $n$-alkanes. The other peaks with lower intensity originate from other groups of hydrocarbons and their derivatives present in the studied diesel.

The chemical changes in the composition of diesel during 30 days of storage with UV irradiation were evident at first glance. The sample subjected to UV exhibited darker color (brownish) and slight turbidity. Moreover, the small amounts of brown gum sediment were observed on the bottom of the vessel. This impurity originated most likely from the polymerization of unsaturated compounds [5].

The UV irradiation during storage influenced significantly the concentration of unsaturated hydrocarbons, mainly olefins, as the least stable compounds among diesel components. Their concentration decreased by $6.7 \%$ for the sample D-30 (compared to the fresh fuel), while for D-30-UV the drastic drop of $62.2 \%$ was noticed. The generally accepted mechanism of degradation of unsaturated compounds involves the oxidation of double bonds, which results in the formation of alkane-1,2-diols or epoxides $[9,10]$. Similarly to unsaturated compounds, the concentration of lighter saturated hydrocarbons (C10-C15) decreased gradually during ageing (see Fig. 2.). This effect was strongly enhanced by the UV irradiation. Most likely, these compounds underwent oxidation processes. It is well known that the oxidation of alkanes results in the formation of alcohols, aldehydes and, ultimately, carboxylic acids [11]. It should, however, be kept in mind that parallel evaporation of both saturated and unsaturated compounds cannot be excluded, as the samples were exposed to the unlimited air access.

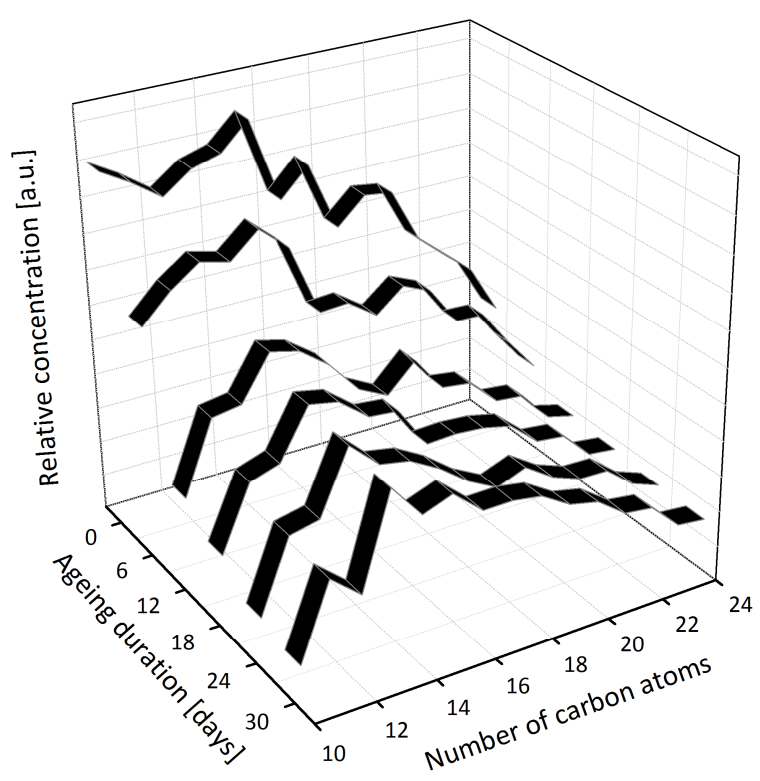

Fig. 2. Time-dependent changes in the relative concentration of $\mathrm{C} 10-\mathrm{C} 24$ unbranched $n$-paraffins determined in the sample aged for 30 days with UV irradiation.

The changes in the relative concentrations of the most abundant groups of the oxygenates formed in the stored diesel after ageing with and without UV irradiation were determined by GC-MS. The chemical structures of chosen oxygen-containing compounds recognized in the D-30-UV sample are depicted in Fig. 3., while the relevant summary concentrations of these groups of O-compounds determined in the D-30 and D-30-UV samples in relation to fresh fuel (D-30), are gathered in Fig. 4. 


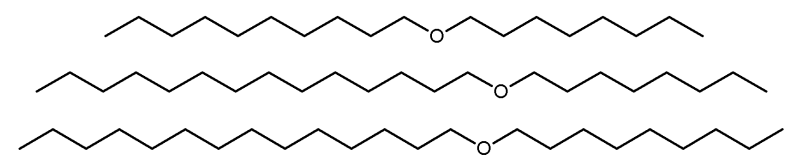

(a)<smiles>CCCCCCCCCCCCCC=O</smiles>

(b)<smiles>CCCCCCCCCCCCCCCCCOC(=O)CCCCCCCCC</smiles>

(c)<smiles>CCCCCCCCC(CO)CCCCCCC</smiles>

(d)<smiles>CCCCCCCCCCCC1OC1CCCCC(C)C</smiles>

(e)

Fig. 3. Structures of chosen oxygenates determined in D-30-UV sample: ethers (a), aldehydes (b), esters (c), alcohols (d), and the compounds containing epoxide ring (e).

Among all the considered oxygenates in the sample of fresh diesel, the relative concentration of alcohols was determined to be the highest. This sample contained also small amounts of aldehydes/ketones and esters as well as traces of carboxylic acids. The ageing for 30 days without UV resulted in slight increase in the concentration of alcohols (by $2.4 \%$ in relation to the concentration in fresh diesel), carbonyl (i.e. aldehydes and ketones) compounds (by $14.1 \%$ ), esters (by 5.1\%), and a noticeable increase in acids content (by $24.8 \%$ ). This corroborates the mechanisms of degradation of hydrocarbons reported elsewhere $[9,10]$.

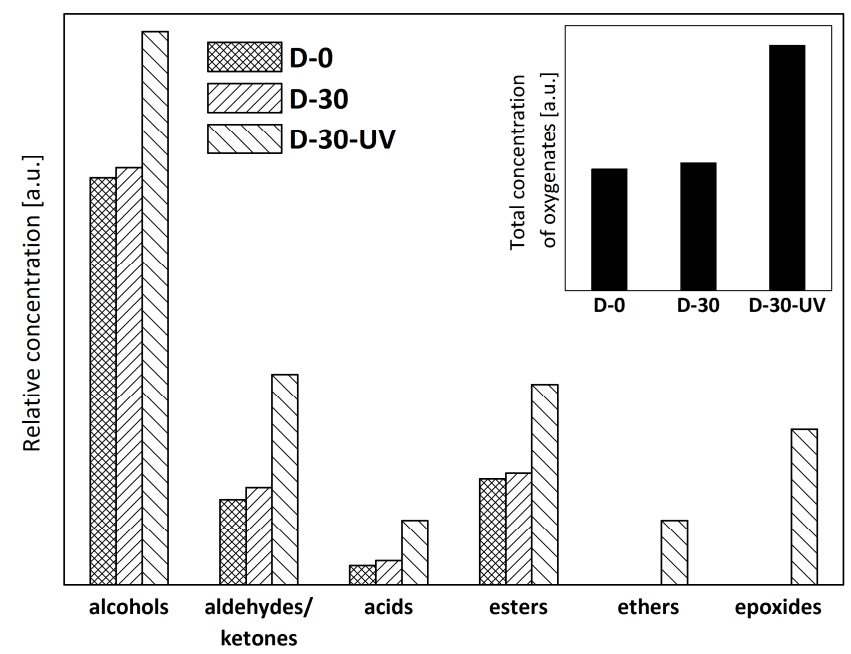

Fig. 4. Relative concentrations of oxygen-containing compounds in D-0, D-30, and D-30-UV samples (inset: the comparison of total summary concentrations of oxygen-containing compounds). 
Although the use of UV irradiation did not influence severely the qualitative composition, it caused more pronounced changes in the concentration of oxygenates, namely the content of carboxylic acids reached $336.3 \%$ compared to D-0 sample, while the concentration of carbonyl compounds was $246.3 \%$. The concentration of esters and alcohols were equal $188.6 \%$ and $135.9 \%$ of the fresh sample, respectively. Additionally, there appeared traces of ethers and epoxides. Considering the total concentration of oxygenates (Fig. 4., inset), one may infer that the ageing for 30 days without UV causes limited changes in the total content of oxygen in diesel (ca. $+5.2 \%$ ), while the additional exposition to ultraviolet light results in almost twice increase in oxygen content $($ ca. $+92.1 \%)$. This, in turn, entails the deterioration of the physicochemical parameters (cf. Section 3.2.). Furthermore, the increased oxygen content may be most likely responsible for the slight turbidity of the aged sample due to limited solubility of certain oxygenates with hydrocarbons in the mother fuel.

\subsection{Impact of ageing on physicochemical parameters}

The effects evaporation of the most volatile fractions of diesel and chemical degradation of the hydrocarbons, which resulted in the formation of the considerable amount of their oxygen-containing derivatives, entailed changes in the atmospheric distillation curve, as presented in Fig. 5.

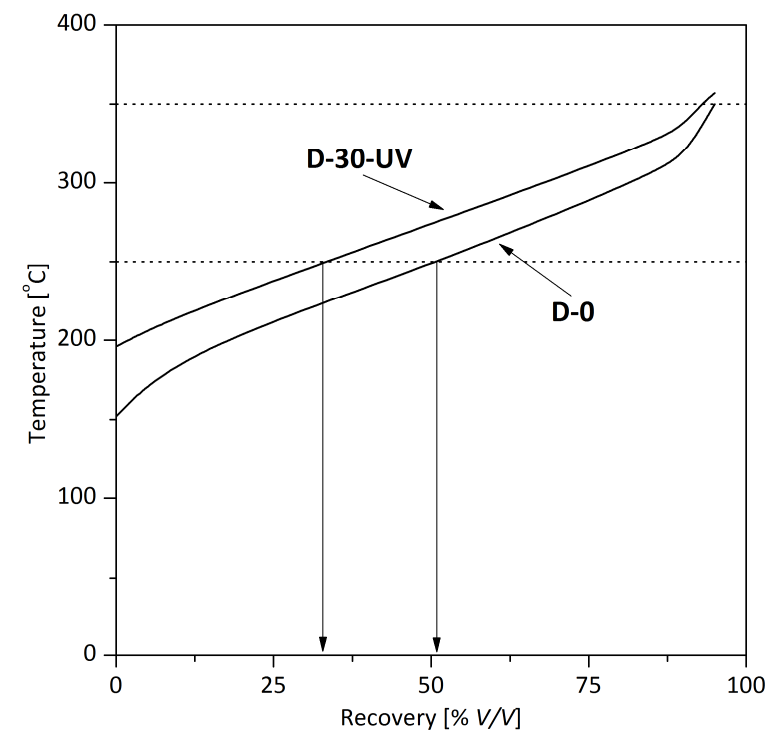

Fig. 5. Distillation characteristics for D-0 and D-30-UV samples.

Naturally, due to the loss of the lightest compounds, the initial boiling point increased drastically from $152{ }^{\circ} \mathrm{C}$ for D-0 to $196{ }^{\circ} \mathrm{C}$ for D-30-UV. Furthermore, the share of the fraction evaporated up to $250{ }^{\circ} \mathrm{C}$ dropped significantly from $52.0 \%(V / V)$ for D-0 to $32.3 \%$ $(V / V)$ for D-30-UV (cf. Table 1). The distillation characteristics for both samples became to be mutually little-by-little closer at the highest evaporation levels. $95 \%(V / V)$ of D-0 sample evaporated up to $350.1{ }^{\circ} \mathrm{C}$, while for D-30-UV the respective temperature reached $356.9{ }^{\circ} \mathrm{C}$. This is in line with the GC-MS results (Fig. 1. and 2.), which revealed the decrease in the concentration of the lightest components of the studied fuel. It should, however, be noted that regardless of the differences in distillation parameters, both samples fulfil the PN-EN 590 standard requirements. 
The crucial physicochemical parameters of fresh diesel oil and the sample after 30 days of ageing including UV irradiation are compiled comprehensively in Table 1.

Table 1. Physicochemical parameters of D-0 and D-30-UV samples compared to PN-EN 590 requirements.

\begin{tabular}{|c|c|c|c|c|c|c|}
\hline \multirow{2}{*}{\multicolumn{2}{|c|}{ Parameter }} & \multirow{2}{*}{ Unit } & \multicolumn{2}{|c|}{ Value } & \multicolumn{2}{|c|}{ Limits } \\
\hline & & & D-0 & D-30- & $\min$. & $\max$ \\
\hline \multicolumn{2}{|c|}{ Cetane number } & - & 53.4 & 47.4 & 51.0 & - \\
\hline \multicolumn{2}{|c|}{ Cetane index } & - & 52.0 & 51.2 & 46.0 & - \\
\hline \multicolumn{2}{|c|}{ Density at $15^{\circ} \mathrm{C}$} & $\mathrm{kg} / \mathrm{m}^{3}$ & 821.5 & 837.6 & 820.0 & 845.0 \\
\hline \multicolumn{2}{|c|}{$\begin{array}{c}\text { Kinematic viscosity } \\
\text { at } 40{ }^{\circ} \mathrm{C}\end{array}$} & $\mathrm{mm}^{2} / \mathrm{s}$ & 2.46 & 3.38 & 2.00 & 4.50 \\
\hline \multicolumn{2}{|c|}{ Flash point } & ${ }^{\circ} \mathrm{C}$ & 58.2 & 90.5 & 56 & - \\
\hline \multicolumn{2}{|c|}{ Cloud point } & ${ }^{\circ} \mathrm{C}$ & -7.0 & -4.0 & - & - \\
\hline \multirow{3}{*}{ 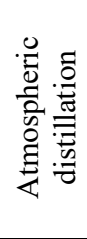 } & $\begin{array}{l}\text { recovered at } \\
250^{\circ} \mathrm{C}\end{array}$ & $\begin{array}{c}\% \\
(V / V)\end{array}$ & 51.0 & 32.3 & - & $<65$ \\
\hline & $\begin{array}{l}\text { recovered at } \\
350{ }^{\circ} \mathrm{C}\end{array}$ & $\begin{array}{c}\% \\
(V / V)\end{array}$ & 94.2 & 94.9 & 85.0 & - \\
\hline & $\begin{array}{l}95 \%(V / V) \\
\text { recovered at }\end{array}$ & ${ }^{\circ} \mathrm{C}$ & 350.1 & 356.9 & - & 360.0 \\
\hline
\end{tabular}

Both parameters associated with the susceptibility of fuel to self-ignition, namely the cetane number and cetane index, decreased slightly after UV-assisted ageing. This may arise from two effects: (i) decrease in paraffin concentration and (ii) a noticeable increase in the content of oxygenates [12]. Obviously, too low cetane number in the case of the D-30-UV sample disqualifies this fuel from use. The ageing influenced also the density and viscosity of the studied sample. The density increased slightly from 821.5 to $837.6 \mathrm{~kg} / \mathrm{m}^{3}$, while the viscosity increased by ca. $37 \%$ from 2.46 to $3.38 \mathrm{~mm}^{2} / \mathrm{s}$. Nevertheless, both parameters meet the PN EN 590 standard. The loss of light components during ageing resulted in a drastic increase in flash point (from 58.2 to $90.5^{\circ} \mathrm{C}$ for D-0 and D-30-UV, respectively), which, naturally, is a beneficial effect from the point of view of fire safety during storage. Contrarily, the ageing had negatively affected the cloud point, raising it by $3{ }^{\circ} \mathrm{C}$ (from -7.0 to $-4.0{ }^{\circ} \mathrm{C}$ ).

\section{Conclusion}

The influence of UV irradiation during long-term storage with unrestricted air access on the chemical composition and crucial physicochemical parameters of base diesel oil was investigated. The significant decrease in the concentration of the lighter fraction of diesel constituents was noticed regardless whether the sample was exposed to UV or not. However, noticeable changes in the composition of oxygen-containing compounds were observed. The GM-MS analysis of the UV-irradiated sample revealed definitely higher concentrations of O-compounds (close to twice) as the products of photodegradation. Among them, the most abundant were carbonyl compounds (esters, acids, and aldehydes), as well as alcohols. Moreover, in the case of the UV-exposed sample, the presence of ethers and epoxides was 
denoted. The irradiated sample exhibited slight turbidity and the formation of certain amounts of gums, what arises from the presence of a relatively high concentration of insoluble oxygenates and polymerization of unsaturated compounds. Finally, it was found that the UV irradiation influenced severely the pivotal physicochemical parameters of diesel. Namely, a slight decrease in the cetane number and cetane index was noticed, while the density and viscosity increased. As the contribution of light components decreased, the flash point increased significantly. The UV-irradiated sample exhibit the cloud point higher by $3{ }^{\circ} \mathrm{C}$ compared to the mother sample. This effect is likely to be caused by the high O-compounds concentration. Nevertheless, the only parameter, which did not meet the standard requirements for the sample aged for 30 days with UV irradiation, was the cetane number.

The research was carried out using the infrastructure of the AGH Centre of Energy, AGH University of Science and Technology. This paper was prepared as a part of the statutory activity of the Faculty of Energy and Fuels at the AGH University of Science and Technology under project No. 11.11.210.373.

\section{References}

1. www.economist.com/blogs/graphicdetail/2018/02/daily-chart-7. [access: 2018-05-15].

2. Global diesel engine market by product, market and region, 5th ed., New York, 2017.

3. S. Parkash, Petroleum fuels manufacturing book, 1st ed., The McGraw-Hill, New York, 2010.

4. W. Stanik, J. Jakóbiec, M. Wądrzyk, R. Janus, Logistyka 5, 569 (2015)

5. R. Banavali, B. Chheda, Chemical basis of diesel fuel stabilization by tertiary alkyl primary amines, Rohm and Haas Company, Deer Park, Texas 77536

6. M. Wądrzyk, R. Janus, M.P. Vos, D.W.F. Brilman, J. Anal. Appl. Pyrolysis 134, 415 (2018)

7. Long term storage of diesel, Fuels News, 2005 BP, Australia

8. A.J. Power, W. Arfelli, R.K. Solly, Fuel stability foam, Report - Department of Defence, Defence Science and Technology Organisation, Materials Research Laboratory, Melbourne, Victoria

9. E. Kwapisz, Biotechnologia 73, 166 (2006)

10. U. Guzik, D. Wojcieszyńska, M. Krysiak, E. Kaczorek, Nafta-Gaz 11, 1019 (2010)

11. J. Czarnocka, M. Odziemkowska, Chemik 69, 771 (2015)

12. Z. Burnus, Nafta-Gaz 9, 849 (2010) 